\section{HEDIS Antidepressant Measures Biased by 2013 Revision}

Most of the nation's health plans and many provider groups use Healthcare Effectiveness Data and Information Set (HEDIS) measures to demonstrate the quality of the care they provide. ${ }^{1}$ Included among the HEDIS measures is the Antidepressant Medication Management (AMM) metric. The AMM metric is designed to assess the adequacy of patients' prescription fill adherence during a 12-week acute phase and a 6-month continuation phase after a new diagnosis and treatment. ${ }^{2}$

For several years, our institution, the Massachusetts General Physicians Organization-a large (2,412 physicians) multispecialty medical group affiliated with a large urban academic quaternary care hospital-has invested in various efforts to improve the quality of depression care. Despite continuing efforts, our performance on the AMM metric has remained below average. We set out to better understand the drivers of our performance by reviewing the electronic medical records (EMR) of our patients who were not meeting the measure.

We identified 292 patients who had their primary care provided at our medical center and were not meeting one or both of the AMM metrics in 2013. A review of our EMR showed that $101(34.5 \%)$ of these patients had received a diagnosis of depression and/or treatment with an antidepressant medicine in the year prior to the index episode.

The HEDIS AMM measure was designed to include only patients with new diagnosis and treatment of depression, in order to provide a reasonably homogenous cohort of patients, so the performance of providers treating this cohort could be compared. Patients with multiple episodes of depression by definition have "chronic depression" and may differ from the cohort of those with new, single episodes. For example, patients with chronic depression may be more likely to be nonadherent to antidepressants than newly diagnosed patients. ${ }^{3,4}$ A lower HEDIS score might therefore be expected for patients in this cohort. Our institution is a recognized center for excellence in psychiatric care and has made an effort to improve rates of depression recognition and treatment. ${ }^{5}$ Thus, we may have higher rates of depression recognition and treatment than other health care systems and may have a cohort enriched with patients with chronic depression. Failing to separate these patients from the standard cohort with new onset single episode depression may explain, at least in part, why our institution rates on the HEDIS AMM are below average.

Previous critiques of the HEDIS AMM have addressed various limitations in the measure but have not addressed issues regarding prior treatment of depression. ${ }^{6,7}$ For example, while in 2013 the AMM criteria were revised to exclude patients with a negative diagnosis history, the requirement that patients have a 90-day negative medication history for antidepressants was retained. ${ }^{2}$ Our observations suggest that this approach may inadvertently produce a selection bias. This bias occurs because new patients are measured without regard to adherence, while inclusion of previously treated patients is related to their adherence history. Previously treated patients are excluded if adherent but included if their nonadherence results in a negative medication history.

Our findings suggest that further revisions in the exclusion criteria may be warranted and/or that the limitations of the measure be carefully considered when the results are displayed. Perhaps the measure should extend the search for evidence of prior antidepressant use beyond the current 90 days before the index episode or screen for evidence of a prior diagnosis of depression. Or, the measure might include all patients with any antidepressant use and/or depression diagnosis beyond the current 90-day cutoff. The limited observations provided here do not suggest how far back the cutoff should be extended; however, since we found evidence of prior treatment or diagnosis a year before the index episodes, studies that evaluate the question of extension of the "clean period" probably should look back a least a year to determine what the impact of including such patients on the measures sensitivity, specificity, and utility might be.

We hope that broader awareness of limitations in the HEDIS AMM metric will enable managed care professionals and providers to improve care for nonadherent patients, particularly where new and chronic episodes of depression may differentially benefit from different interventions. These findings suggest an opportunity to improve the AMM measures so that better measures can guide more effective improvement efforts and ultimately improve patient outcomes.

\section{Kyungwan Hong}

PharmD Candidate

MS Candidate in Pharmacoepidemiology/Pharmacoeconomics

University of Rhode Island College of Pharmacy

kyungwan_hong@my.uri.edu

\section{Greg Low, RPh, PhD}

Director, Pharmacy Quality and Utilization Program

Massachusetts General Hospital

Massachusetts General Physicians Organization

\section{Jeffrey B. Weilburg, MD}

Associate Medical Director,

Massachusetts General Physicians Organization

Director, Clinical Neuropsychiatry, Massachusetts General Hospital Assistant Professor of Psychiatry, Harvard Medical School

\section{DISCLOSURES}

The authors declare no conflicts of interest.

Study concept and design were primarily contributed by Low and Weilburg, with help from Hong. Data collection was performed mainly by Hong, assisted by Low, and analysis was carried out primarily by Hong, with help from Low and Weilburg. This letter was written by Hong, Low, and Weilburg and revised equally by all the authors. 


\section{REFERENCES}

1. National Comittee for Quality Assurance. The state of health care quality 2013. October 2013. Available at: http://www.ncqa.org/Portals/0/Newsroom/ SOHC/2013/SOHC-web_version_report.pdf. Accessed March 17, 2015.

2. National Committee for Quality Assurance. HEDIS 2013. Volume 2: technical specifications. Available at: http://www.ncqa.org/

HEDISQualityMeasurement/HEDISMeasures/HEDIS2013.aspx. Accessed March 17, 2015.

3. Demyttenaere K, Adelin A, Patrick M, Walthère D, Katrien de B, Michèle $\mathrm{S}$. Six-month compliance with antidepressant medication in the treatment of major depressive disorder. Int Clin Psychopharmacol. 2008;23(1):36-42.
4. Tamburrino MB, Nagel RW, Chahal MK, Lynch DJ. Antidepressant medication adherence: a study of primary care patients. Prim Care Companion J Clin Psychiatry. 2009;11(5)205-11.

5. U.S. News Best Hospitals 2014-15. U.S. News \& World Report. 2014. Available at: http://health.usnews.com/best-hospitals/rankings. Accessed March 17, 2015.

6. Crownover BK. Referral bias and other perspectives on the HEDIS measuring stick for quality of care in depression treatment. J Manag Care Pharm. 2006;12(1):76-77. Available at: http://amcp.org/data/jmcp/editorial_76-77.pdf.

7. Rost K, Dickinson LM, Fortney J, Westfall J, Hermann RC. Clinical improvement associated with conformance to HEDIS-based depression care. Ment Health Serv Res. 2005;7(2):103-12. 